\title{
Simulated encounters with a novel competitor reveal the potential for maladaptive behavioural responses to invasive species
}

\author{
T. Champneys $(\mathbb{D} \cdot$ K. Ferry $\cdot$ S. Tomkinson $\cdot$ M. J. Genner $\cdot$ C. C. Ioannou
}

Received: 14 April 2021/Accepted: 16 November 2021/Published online: 30 November 2021

(C) The Author(s) 2021

\begin{abstract}
During the early stage of biological invasions, interactions occur between native and nonnative species that do not share an evolutionary history. This can result in ecological naïveté, causing native species to exhibit maladaptive behavioural responses to novel enemies, leading to negative consequences for individual fitness and ecosystem function. The behavioural response of native to nonnative species during novel encounters can determine the impact of non-native species, and restrict or facilitate their establishment. In this study we simulated novel encounters between a widespread invasive fish species, the Nile tilapia (Oreochromis niloticus), and a threatened native Manyara tilapia (Oreochromis amphimelas). In the first experiment single adult $O$. niloticus were presented with a stimulus chamber (a transparent plastic cylinder) which was empty during control trials and contained a pair of juvenile $O$. amphimelas in stimulus trials. In the second experiment, the reciprocal set up was used, with pairs of juvenile $O$. amphimelas as the focal species and adult $O$. niloticus as the stimulus. Both species approached
\end{abstract}

Supplementary Information The online version contains supplementary material available at https://doi.org/10.1007/ s10530-021-02690-6.

T. Champneys $(\bowtie) \cdot$ K. Ferry $\cdot$ S. Tomkinson •

M. J. Genner · C. C. Ioannou

School of Biological Sciences, Life Sciences Building,

University of Bristol, 24 Tyndall Avenue, Bristol, UK

e-mail: toby.champneys@bristol.ac.uk the stimulus chamber more readily during stimulus trials, a behavioural response which would increase the prevalence of interspecific interactions in situ. This included physical aggression, observed from the competitively dominant $O$. niloticus towards $O$. amphimelas. Despite an initial lack of fear shown by O. amphimelas, close inspection of the stimulus chamber often resulted in an energetically costly dart response. Under field conditions we predict that naïve native individuals may readily approach $O$. niloticus, increasing the likelihood of interactions and exacerbating widely reported negative outcomes.

Keywords Naïveté · Invasion ecology · Interspecific competition · Alien species · Oreochromis amphimelas · Oreochromis niloticus · Nile tilapia

\section{Introduction}

The establishment of species in areas outside of their native range can have wide ranging effects on ecosystems (Clavero and García-Berthou 2005). In some cases, non-native species have driven population declines and extinctions of native species following their establishment (Sax and Gaines 2008), while in others they have had limited impact or even provided desirable ecosystem functions (Richardson et al. 2000; Schlaepfer et al. 2011; Anton et al. 2019). This 
variation in impact is thought to be determined largely by the character and strength of interactions with native species (Carthey and Banks 2014). Studying interactions between native and non-native species can therefore be used to target mitigation strategies towards the most harmful invaders (Parker et al. 1999) and to inform policy decisions which may limit the spread of species with high potential for negative impact (Kulhanek et al. 2011).

During the early stage of invasion, novel interactions occur between native and non-native species (Schlaepfer et al. 2005). This can result in ecological naïveté, where native species are unable to respond appropriately to the level of threat posed by non-native species and exhibit maladaptive behavioural responses as a result (Carthey and Banks 2014). Naïveté can affect the outcome of any antagonistic interaction, but the majority of research to date has focused on predator-prey interactions (Carthey and Banks 2014). This work has highlighted how naïveté to both nonnative predators and prey can result in increased mortality for native species, impacting ecosystem function (Llewelyn et al. 2009; Robbins et al. 2013; Papacostas and Freestone 2019; Anton et al. 2020). Alternatively, misidentification of non-predatory invasive species can result in unnecessary energy expenditure or missed opportunities to forage (Carthey and Blumstein 2018). While the selective forces relating to predator-prey interactions are particularly strong, naïveté can affect the outcome of any antagonistic interaction, resulting in consequences for individual and population fitness. For example, exploitative and interference competition shape community structure within ecosystems (Rowles and O'Dowd 2007), and naïveté to a novel competitor can influence the outcome of competitive interactions (Harrington et al. 2009; Heavener et al. 2014). Across all antagonistic interactions, maladaptive behavioural responses resulting from naïveté can lead to a number of harmful outcomes including predation (Salo et al. 2007), ingestion of toxic prey (Letnic et al. 2008), restricted access to resources (Heavener et al. 2014), increased disease and parasite transmission (Chalkowski et al. 2018), and hybridisation (Bleeker et al. 2007). These outcomes are closely linked to fitness and survival, and the need to explore how naïveté influences a wide range of antagonistic interactions has been highlighted in several publications (Carthey and Banks 2014; Heavener et al. 2014).
The initial stages of invasion are thought to play a particularly important role in determining the outcome of biological invasions (Chapple et al. 2012). This heightens the importance of early encounters, where an appropriate response to novel species may limit the establishment and impact of these non-native species, while maladaptive behavioural responses may lead to harmful outcomes for native species and facilitate the spread of the non-native species. Furthermore, naïveté is highest during early-encounters, limiting the available time for adaptive changes in response to nonnative species (Phillips and Shine 2004). The majority of research on biological invasions has focused on well-established invasive populations, yet it is estimated that less than $10 \%$ of non-native species that are released will become established (Kolar and Lodge 2001). Research into interactions between native and non-native species during early encounters may therefore improve understanding of the mechanisms that govern success and failure at the establishment step of invasions. Investigating such interactions in the field is challenging because the precise timing of nonnative species introductions is not typically known, and so interactions between native and non-native species have already occurred frequently before they can be investigated. Experimental approaches can therefore be used to investigate interspecific interactions which allows for control of prior experience.

In this study, we simulated novel interactions between a widespread invasive species (Nile tilapia Oreochromis niloticus) and a threatened tilapia native to Tanzania (Manyara tilapia Oreochromis amphimelas). Oreochromis niloticus has been introduced to several catchments containing O. amphimelas, and the two can be found in sympatry (Shechonge et al. 2019). Currently, little is known about the timing and history of this specific invasion, and limited research has been conducted on the natural history of $O$. amphimelas. However, both $O$. niloticus and $O$. amphimelas are mouthbrooders and are largely microphagous (Trewavas and Fryer 1965), suggesting strong resource overlap and the potential for competition over the limited resources of food and spawning areas. There is limited evidence for predation of native congeners by $O$. niloticus, yet the potential for harmful effects resulting from interactions with $O$. niloticus has been documented for many species (Martin et al. 2010; Sanches et al. 2012), including O. amphimelas (Champneys et al. 2020; Wing et al. 2020). For 
example, $O$. niloticus and $O$. amphimelas have been shown to compete aggressively for shelter under experimental conditions, with $O$. niloticus dominating these interactions (Champneys et al. 2020). Thus, naivete during early encounters with this novel competitor could lead to harmful outcomes for naïve $O$. amphimelas in situ.

In the first experiment, we presented an adult $O$. niloticus with a pair of juvenile $O$. amphimelas in a clear chamber, enabling us to determine how $O$. niloticus may first respond to native species when entering a novel habitat. Based on previous research we predicted $O$. niloticus to boldly approach the stimulus area and show aggression towards the chamber when it contained O. amphimelas. In the second experiment we presented pairs of juvenile $O$. amphimelas with an adult $O$. niloticus in a clear chamber, providing insight into the response of $O$. amphimelas as a naïve native species. Little is known about how native tilapia species respond to novel competitors and collectively the results of the two experiments allow discussion of the potential impact that different behavioural responses could have on the fitness and survival of the native species.

\section{Methods}

Experimental subjects and housing

Oreochromis niloticus subjects were purchased from a commercial aquaculture supplier (Fish Farm UK, London) and $O$. amphimelas subjects were reared at the University of Bristol and were second generation from wild caught stock. Wild individuals were originally caught from Lake Manyara $\left(3^{\circ} 36^{\prime} 29.5^{\prime \prime} \mathrm{S}\right.$ $35^{\circ} 49^{\prime} 01.2^{\prime \prime} \mathrm{E}$, precise coordinates unknown). Oreochromis niloticus are typically introduced via intentional stocking events, or through unintentional release from aquaculture (Canonico et al. 2005). Therefore, we used adult $O$. niloticus from aquaculture stock in this experiment which are likely to be the first individuals to interact with native species during the early stage of $O$. niloticus colonisation. Juvenile $O$. amphimelas from wild stock were used as this is when the size difference between the two species is largest allowing us to investigate a scenario where $O$. amphimelas may perceive $O$. niloticus as a predator. While little is known about the natural history of $O$. amphimelas, juvenile tilapias are often found in groups and therefore a pair of $O$. amphimelas was used to measure their social response to O. niloticus which is likely to be an ecologically relevant response to threat in situ. Prior to this experiment, the $O$. niloticus subjects were used in one experiment where they interacted with sized matched $O$. amphimelas for a single 15-min trial (Champneys et al 2020), while the $O$. amphimelas had no prior experience interacting with $O$. niloticus. Oreochromis niloticus subjects had an average total length of $83.13 \pm 7.21 \mathrm{~mm}$ and $O$. amphimelas had an average total length of $34.77 \pm 7.26 \mathrm{~mm}$. Fish were housed in a recirculating aquarium at the University of Bristol for at least three months prior to testing. $O$. niloticus were housed in 190L tanks with 30-40 individuals per tank and $O$. amphimelas were housed in 90L housing tanks with 100-110 individuals per tank. Housing tanks contained a variety of plastic plants and pipes to provide enrichment, reduce stereotypic behaviours and improve welfare (Favero Neto and Giaquinto 2020). Both species were fed daily with a mixed diet consisting of chopped prawn, brine shrimp, mysis shrimp and vegetable diet (Tropical Marine Centre, Chorley Wood, UK), ZM Large Premium Granular feed (Tecniplast, London, UK), TetraMin flake (Tetra, Melle, Germany), frozen bloodworm (CC Moore \& Co, Templecome, UK) and Gamma TM Krill Pacifica. On trial days, fish were only fed after experiments finished to standardise hunger during trials. Housing tanks were maintained at a temperature of $26-28{ }^{\circ} \mathrm{C}$. Lighting conditions were 12:12 h light: dark cycle to replicate conditions in the tropics. Trials took place during October and November 2019.

\section{Experimental set up and protocol}

A single experimental tank $(136 \mathrm{~cm}$ long $\times 72 \mathrm{~cm}$ wide $\times 40 \mathrm{~cm}$ high) was divided lengthways with a $136 \mathrm{~cm}$ long $\times 30 \mathrm{~cm}$ high opaque central divider into two identical experimental sections (Fig. 1). The divider was a fixed structure sealed to the tank to prevent water movement between the sections. Each section was filled daily with 49L of housing tank water to a depth of $10 \mathrm{~cm}$. Each section of the tank had two distinct zones and three virtual zones which were added digitally for the purposes of analysis (Fig. 1). The shelter zone $(21 \mathrm{~cm} \times 36 \mathrm{~cm})$ was situated at one of the long ends of the tank, covered by a $5 \mathrm{~mm}$ black 


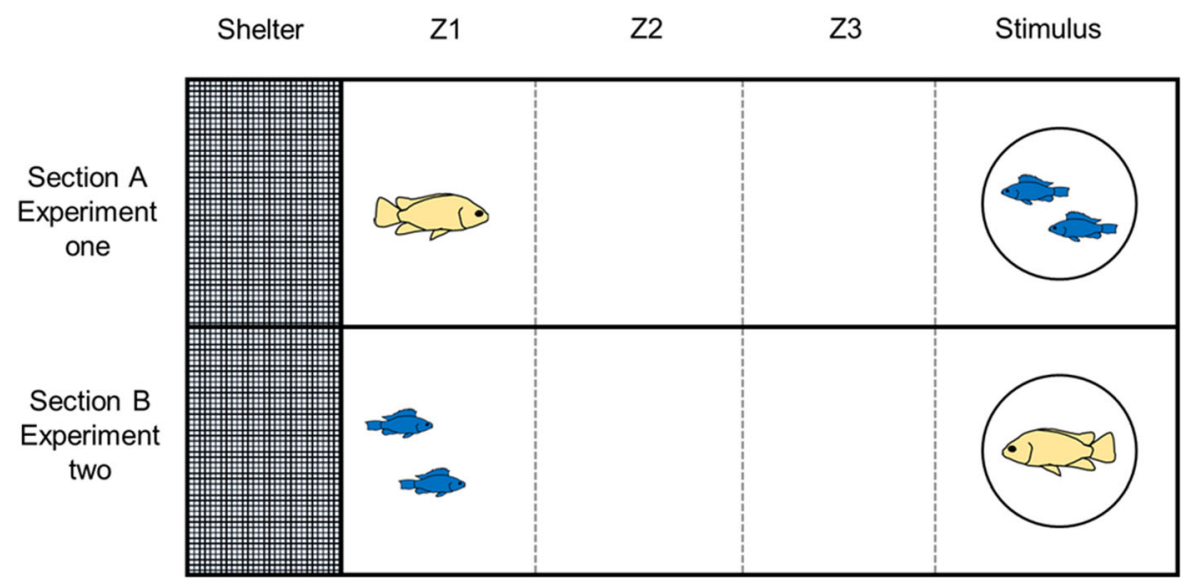

Fig. 1 Overhead view of the experimental set up used in experiments one and two (not to scale). The tank was split lengthways using an opaque divider. Z1, Z2 and Z3 represent the three virtual zones in the centre of the tank which were used for

mesh plastic sheet $20 \mathrm{~cm}$ above the water level. At the opposite end was the stimulus zone $(32 \mathrm{~cm} \times 36 \mathrm{~cm})$, which had a clear plastic cylinder in its centre $(16 \mathrm{~cm}$ diameter $\times 25$ high) which was filled with water to the same height as the rest of the tank. The section in between contained the three additional virtual zones (zone 1: $19 \mathrm{~cm} \mathrm{x} 36 \mathrm{~cm}$, zone 2: $26 \mathrm{~cm} \mathrm{x} 36 \mathrm{~cm}$ and zone 3: $27 \mathrm{~cm} \times 36 \mathrm{~cm})$. A water heater and filter (Eheim 2213) were used to maintain water quality and temperature and were switched off during trials to avoid disturbance, with water temperature remaining at a constant $26{ }^{\circ} \mathrm{C}$.

The experimental setup was used to run two separate experiments concurrently. In experiment one, a single $O$. niloticus was the focal subject, and the clear cylinder in the stimulus zone contained two size-matched $O$. amphimelas in stimulus trials and was empty in control trials. In experiment two, a sizematched pair of $O$. amphimelas were the focal species, with one randomly designated to be the focal subject and have its behaviour monitored. The clear cylinder contained a single $O$. niloticus in the stimulus trials and was empty in control trials. Experiment one took place in section A and experiment two in section B (Fig. 1). Stimulus individuals were always focal individuals from the previous trial so were partially acclimatised to the arena. Each trial day thus began with a control treatment in both experiments. From the first experiment of the day onwards, control or stimulus treatments were randomly selected before video analysis dashed grey lines represent digital divisions black circles represent the transparent cylinders which contained the stimulus subjects in stimulus trials and were empty in control trials

each trial at a ratio of two stimulus trials to one control trial. This ratio was used to increase the sample size of stimulus trials, allowing separate analyses on this subset of the data to be run with sufficient statistical power, which included the size of the stimulus fish as a covariate.

At the start of each trial, focal individuals from the previous trial were either placed in the clear cylinder of the other section (for stimulus trials) or placed into dedicated housing tanks to avoid reusing individuals (for control trials). Focal individuals were then netted haphazardly from their housing tank using a hand net and transferred to the shelter zone of the experimental tank. Once all fish for both experiments had been transferred, the 12-min recording period began. After use as either focal or stimulus, all individuals had their total length measured using callipers and were transferred to the housing tanks for used fish.

Video recording and analysis

The 12-min trial was recorded by an overhead GoPro Hero 6 camera (linear field of view, 30 frames per second, $1280 \times 720$ resolution, GoPro Inc., San Mateo, CA, USA) situated $76 \mathrm{~cm}$ above the water surface. This filmed both experiments in a single video. Each video was analysed separately for each experiment using BORIS software v 9.7.4 by two observers (Friard and Gamba 2016). This software is used manually by the observer to record a previously 
defined ethogram of behaviours as either single time point or state events. In experiment two, one of the two O. amphimelas was randomly assigned as the test fish to be monitored and only the behaviour of this individual was recorded. The ethogram of behaviours was designed based on similar studies of fish behaviour and the full definition of each behaviour can be found in Table 1. In experiment one, the number of times the focal $O$. niloticus approached the stimulus, circled the stimulus, or showed aggression towards the stimulus was recorded. In experiment two, the number of times the focal $O$. amphimelas approached the stimulus and showed a flight response (i.e. darted away) from the stimulus was recorded. The behaviours recorded differed between the species due to unique behaviours being exhibited by each species. Flight responses were not exhibited by $O$. niloticus and circle and aggression behaviours were not exhibited by $O$. amphimelas. The time taken for each of these behaviours to first occur in each trial was also recorded for both experiments. In both experiments, the location of the focal subject (shelter, zone 1, zone 2, zone 3 or stimulus zone) was recorded throughout the trial, and this provided the time taken to first leave the shelter and the time taken to first enter the stimulus zone. In experiment two, the duration of time that the focal $O$. amphimelas spent in the same zone as the other $O$. amphimelas individual was recorded to provide a measure of sociability. The duration of time spent stationary by the focal individual was also recorded in both experiments to provide a measure of activity. The behaviours recorded are relevant in the context of ecological naivete and interactions between competitors because a willingness to approach a novel competitor would increase the frequency of interactions while avoidance behaviour would decrease the frequency of interactions. Thus, approach and dart events along with the time taken to leave the shelter and enter the stimulus zone provided a measure of this willingness to approach the novel species. Additionally, circling and aggressive behaviours provided a measure of the likely outcome of interactions between the species, if the plastic chamber had not prevented physical contact. The final data set included 79 trials for experiment one (53 stimulus, 23 control), and 74 for experiment two (49 stimulus, 25 control), after one from experiment one and six from experiment two were discarded due to video recording failures.

\section{Statistical analysis}

All analyses were conducted using $\mathrm{R}$ version 3.6.3 ( $\mathrm{R}$ Core Team 2020). In both experiments, the time to response variables were analysed using Cox Proportional-Hazards Models using the 'coxph' function in the package 'survival' (Therneau 2020). This tests how the likelihood of an event is influenced by a set of risk factors at any given time over the measured duration. In experiment one, the events were the time taken to first enter the stimulus zone, approach the stimulus, and circle the stimulus. In experiment two, the events were the time taken for the focal subject to first leave the shelter, enter the stimulus zone, and approach the stimulus. In both experiments, the measured duration was the length of the experiment (720 s). The risk factors were the fixed effects which were treatment (control or stimulus) and test subject body size. In experiment one, subject body size was the total length of the focal $O$. niloticus, in experiment two it was the mean total length of the $O$. amphimelas pair. The data were then subset to only include stimulus trials, and the same dependent variables were analysed using the same method, removing the treatment term but including stimulus body size as a

Table 1 Definitions of behaviours recorded from the videos

\begin{tabular}{|c|c|c|}
\hline Behaviour & Definition & Used in \\
\hline Approach & $\begin{array}{l}\text { The focal subject swims towards the stimulus until it is within less than one of its own body } \\
\text { lengths (Frommen et al. 2009; Bevan et al. 2018) }\end{array}$ & $\begin{array}{l}\text { Experiment one and } \\
\text { experiment two }\end{array}$ \\
\hline Circle & The focal subject circles around the entire circumference of the stimulus & Experiment one \\
\hline Aggression & $\begin{array}{l}\text { The focal subject swims rapidly towards the stimulus until it makes contact with the } \\
\text { stimulus chamber (Ros et al. 2006; Champneys et al. 2018; Szopa-Comley et al. 2020) }\end{array}$ & Experiment one \\
\hline Dart & The focal subject swims rapidly away from the stimulus (Kimbell and Morrell 2015) & Experiment two \\
\hline
\end{tabular}


model covariate to assess whether behavioural responses were influenced by the size of the stimulus fish.

The proportional hazards assumption is a central assumption of these models, and we tested it using the cox.zph function which revealed no violation for any of the models. The 'ggcoxdiagnostics' command in the package 'survminer' was used to test for influential observations (Kassambara et al. 2019) and this assumption was satisfied in all cases. To test for nonlinearity, models were run with a smoothing parameter fitted to the linear covariate focal subject body size using a penalised spline method with the function pspline function in the package 'survival'. This method smooths covariates which have non-linear effects on the dependent variable, improving the evaluation of the relationship between the predictor variable and the dependent variable. Models with and without spline terms were then compared using AICc (Alkaike Information Criterion corrected (AICc) for small sample sizes) with the function AICctab in package 'bbmle' (Bolker B, R Core Team, 2017; following methods in Roshani and Ghaderi 2016). In all cases, models without the spline term were more likely, confirming that fitting linear relationships was more appropriate. Packages 'survival' and 'survminer' were used to visualise the results.

In experiment one, the time spent stationary (a measure of activity) by the O. niloticus and the number of approach, circle and aggression events were analysed using Generalised Linear Models (GLMs). A Gaussian family was used for activity using the $\mathrm{glm}$ function with the default family, while a negative binomial family was used for approach, circle and aggression events using the glm.nb function in the package'MASS' (Venables and Ripley 2002). In experiment two, the time spent in the same zone by the two $O$. amphimelas (sociability), the time spent stationary by the focal $O$. amphimelas (activity), the number of approach events, and whether the trial contained at least one dart event, were also analysed using GLMs. A Gaussian family was used for sociability, a binomial family was used for dart events and a negative binomial family was used for activity and approaches. In both experiments, treatment (stimulus or control), focal body size (total length of the focal $O$. niloticus or mean total length of the $O$. amphimelas pair) and an interaction term between these two variables were included as covariates. In order to assess the effect of stimulus body size within stimulus trials, the data were then subset to only include stimulus trials. With this dataset, the same four dependent variables per experiment were analysed using GLMs, and in both experiments, the body size of the stimulus fish, focal body size, and an interaction term including these two variables were included as covariates. For this analysis, negative binomial GLMs were used for all four dependent variables in experiment one. In experiment two, negative binomial GLMs were used for sociability, activity and number of approaches while GLMs with a binomial family were used for dart events.

The default link functions were used in each GLM. Plots of fitted values versus residuals and the distribution of residuals versus a normal distribution using a QQ plot were used to test the model assumptions in the Gaussian models. The overdispersion statistic was calculated for the negative binomial models to ensure it fell between 0.5 and 2 , indicating that there was no overdispersion. Once these assumptions were satisfied, a set of models containing all combinations of the covariates and their interaction terms were run. These models were compared based on the Akaike information criterion corrected for small sample sizes (AICc) using the function AICctab to determine the models with most support. A difference in AICc between two models greater than two (i.e. $\triangle \mathrm{AICc}>2$ ) indicates strong support for the model with lower AICc being the more likely model given the data (Burnham and Anderson 2004). Akaike weights were also calculated, these provide a conditional probability for each model further aiding interpretation of the level of support for each model (Wagenmakers and Farrell 2004). Therefore, by running a set of models with and without explanatory variables of interest, the variables which provide the best explanation of variation in the dependent variable can be inferred.

\section{Results}

Experiment one

Time taken to enter the stimulus zone, approach the stimulus and circle the stimulus

The likelihood of the focal O. niloticus entering the stimulus zone did not differ significantly between 
trials with $O$. amphimelas as the stimulus and control trials without $O$. amphimelas (Cox ProportionalHazards model, coef $=0.51$, $\exp ($ coef $)=1.66$, lower $95 \% \mathrm{CI}=0.96$, upper $95 \% \mathrm{CI}=2.86, P=0.069$; Fig. 2a). However, O. niloticus were more likely to approach $($ coef $=0.7, \exp ($ coef $)=2.01$, lower $95 \%$ $\mathrm{CI}=1.11$, upper $95 \% \mathrm{CI}=3.65, P=0.021$; Fig. $2 \mathrm{~b}$ ) and circle $($ coef $=2.1, \exp (\operatorname{coef})=8.14$, lower $95 \%$ $\mathrm{CI}=1.93$, upper $95 \% \mathrm{CI}=34.4, P=0.004$; Fig. $2 \mathrm{c}$ ) the stimulus in trials with $O$. amphimelas. The size of the $O$. niloticus did not affect the likelihood of entering the stimulus zone $($ coef $=0.01, \exp ($ coef $)=1.01$, lower $95 \% \mathrm{CI}=0.98$, upper $95 \% \mathrm{CI}=1.05$, $P=0.53), \quad$ approaching $\quad$ (coef $=0.006, \quad \exp (-$ coef $)=1.01$, lower $95 \% \mathrm{CI}=0.97$, upper $95 \% \mathrm{CI}=$ $1.05, P=0.76$ ) or circling the stimulus (coef $=-0.03$, $\exp ($ coef $)=0.97$, lower $95 \% \mathrm{CI}=0.92$, upper $95 \%$ $\mathrm{CI}=1.03, P=0.31$ ). In the stimulus trials only, the likelihood of entering the stimulus zone (coef $=0.01$, $\exp ($ coef $)=1.01$, lower $95 \% \mathrm{CI}=0.97$, upper $95 \%$ $\mathrm{CI}=1.06, \quad P=0.48), \quad$ approaching the stimulus (coef $=0.01, \exp ($ coef $)=1.01$, lower $95 \% \mathrm{CI}=0.97$, upper $95 \% \mathrm{CI}=1.06, P=0.63$ ), and circling the stimulus (coef $=-0.008$, exp $($ coef $)=0.99$, lower $95 \%$ $\mathrm{CI}=0.94$, upper $95 \% \mathrm{CI}=1.05, P=0.78$ ) was not significantly affected by the mean body size of the $O$. amphimelas pair used as the stimulus.

\section{Activity}

For the time spent stationary, AICc values and Akaike weights indicated strongest support for the model containing only focal body size as a covariate (Table 2), suggesting that activity levels were not significantly different between treatments (Fig. 3a). In the stimulus trials only, AICc values and Akaike weights also indicated strong support for the model containing only focal body size, suggesting no effect of stimulus body size on the time spent stationary by O. niloticus (Table 3). In both analyses, larger fish were shown to have lower activity than smaller fish.

\section{Approach events}

AICc values and Akaike weights indicated strongest support for the model containing only treatment as a fixed effect (Table 2), where approaches were more frequent toward the $O$. amphimelas than the empty cylinder in the control trials (Fig. 3b). In the stimulus trials only, AICc values and Akaike weights indicate support for the model containing the interaction term between stimulus body size and focal body size. Support for this model suggests that the effect of stimulus body size on the number of approaches may vary depending on focal body size. However, the model including only stimulus body size, also has strong support $(\triangle \mathrm{AICc}<2)$, where the number of approaches increased as stimulus body size increased (Table 3).

Circle events

AICc values and Akaike weights indicated strongest support for the model containing only treatment as a
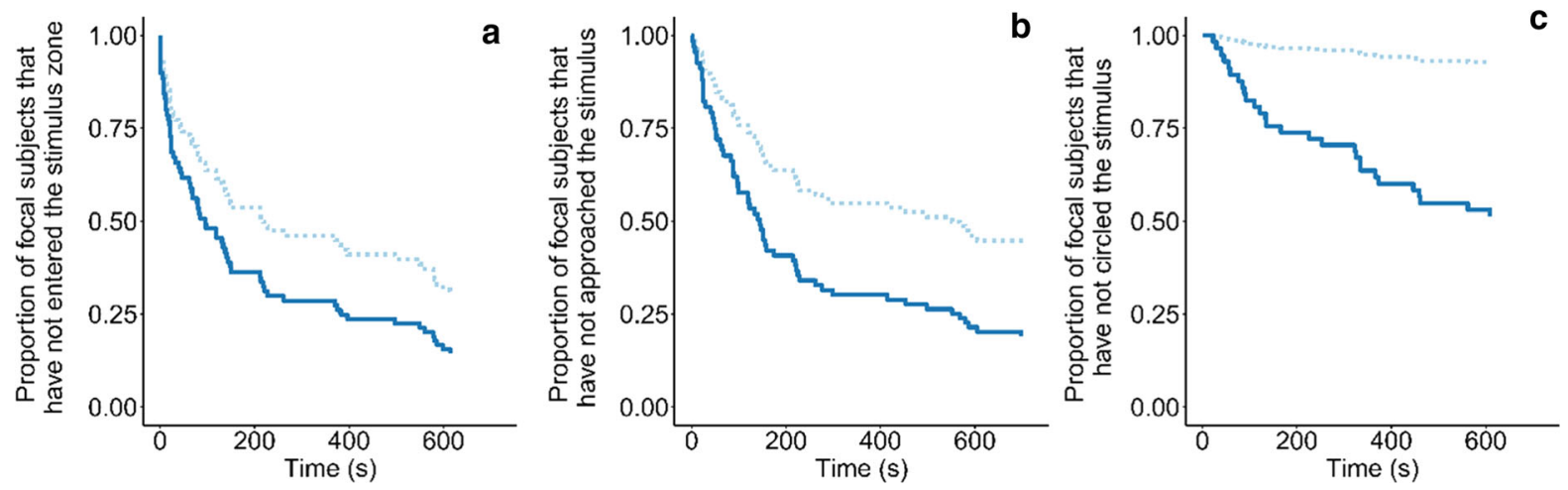

Fig. 2 The likelihood of $O$. niloticus a entering the stimulus zone, $\mathbf{b}$ approaching the stimulus, and $\mathbf{c}$ circling the stimulus in control and stimulus trials in experiment one 
Table 2 Model comparisons for GLMs used in experiment one to analyse how the dependent variables of $O$. niloticus activity, approach, circle, and aggression were affected by five different combinations of the fixed effects treatment and focal fish body size

\begin{tabular}{|c|c|c|c|c|c|c|}
\hline Dependent variable & Model & Explanatory variables & $\mathrm{AICc}$ & $\Delta \mathrm{AICc}$ & df & Akaike weight \\
\hline \multirow[t]{5}{*}{ Activity (Gaussian) } & $\mathrm{m} 4$ & Focal body size & 1031.4 & 0 & 3 & 0.32 \\
\hline & $\mathrm{m} 2$ & Treatment + Focal body size & 1032 & 0.5 & 4 & 0.25 \\
\hline & $\mathrm{m} 1$ & Treatment $*$ Focal body size & 1032.4 & 1 & 5 & 0.20 \\
\hline & $\mathrm{m} 3$ & Treatment & 1033.5 & 2 & 3 & 0.12 \\
\hline & m5 & Null & 1033.6 & 2.2 & 2 & 0.11 \\
\hline \multirow[t]{5}{*}{ Approach events (Negative binomial) } & $\mathrm{m} 3$ & Treatment & 403.1 & 0 & 3 & 0.48 \\
\hline & $\mathrm{m} 2$ & Treatment + Focal body size & 403.6 & 0.5 & 4 & 0.37 \\
\hline & $\mathrm{m} 1$ & Treatment $*$ Focal body size & 405.4 & 2.3 & 5 & 0.15 \\
\hline & $\mathrm{m} 4$ & Focal body size & 420.3 & 17.2 & 3 & $<0.001$ \\
\hline & $\mathrm{m} 5$ & Null & 421.4 & 18.3 & 2 & $<0.001$ \\
\hline \multirow[t]{5}{*}{ Circle events (Negative binomial) } & $\mathrm{m} 3$ & Treatment & 193.2 & 0 & 3 & 0.53 \\
\hline & $\mathrm{m} 2$ & Treatment + Focal body size & 194.1 & 0.9 & 4 & 0.34 \\
\hline & $\mathrm{m} 1$ & Treatment $*$ Focal body size & 195.9 & 2.7 & 5 & 0.13 \\
\hline & $\mathrm{m} 4$ & Focal body size & 206.4 & 13.3 & 3 & $<0.001$ \\
\hline & $\mathrm{m} 5$ & Null & 206.7 & 13.6 & 2 & $<0.001$ \\
\hline \multirow[t]{5}{*}{ Aggression events (Negative binomial) } & $\mathrm{m} 2$ & Treatment + Focal body size & 205.9 & 0 & 4 & 0.51 \\
\hline & $\mathrm{m} 3$ & Treatment & 206.8 & 0.9 & 3 & 0.33 \\
\hline & $\mathrm{m} 1$ & Treatment $*$ Focal body size & 208.1 & 2.3 & 5 & 0.16 \\
\hline & $\mathrm{m} 4$ & Focal body size & 231 & 25.2 & 3 & $<0.001$ \\
\hline & $\mathrm{m} 5$ & Null & 232.7 & 26.8 & 2 & $<0.001$ \\
\hline
\end{tabular}

fixed effect (Table 2), where the circle events were more frequent in stimulus than control trials (Fig. 3c). In the stimulus trials only, AICc values and Akaike weights indicated strong support for the null model (Table 3).

\section{Aggression events}

AICc values and Akaike weights indicated strongest support for the model containing treatment and focal body size as fixed effects (Table 2). Strong support is also given to the model containing only treatment $(\triangle \mathrm{AICc}<2)$, with the aggression events being far more frequent in the stimulus than the control trials (Fig. 3d). In the stimulus trials only, AICc values and Akaike weights indicated strong support for the model containing focal body length as a covariate (Table 3), although there was also strong support for the null model $(\triangle \mathrm{AICc}<2)$, suggesting that focal and stimulus body sizes had weak effects on the number of aggression events in the stimulus trials (Table 3).
Experiment two

Time taken to leave the shelter, enter the stimulus zone, and approach the stimulus

The likelihood of the focal O. amphimelas individual leaving the shelter did not differ significantly between stimulus and control trials (Cox Proportional-Hazards model, coef $=0.48$, $\exp ($ coef $)=1.62$, lower $95 \%$ $\mathrm{CI}=0.98$, upper $95 \% \mathrm{CI}=2.69, P=0.058$; Fig. $4 \mathrm{a}$ ). However, $O$. amphimelas were significantly more likely to enter the stimulus zone (coef $=0.55$, exp(coef) $=1.73$, lower $95 \% \mathrm{CI}=1.01$, upper $95 \% \mathrm{CI}=$ 2.99, $P=0.045$; Fig. 4b) and approach the stimulus $($ coef $=1.41, \exp ($ coef $)=4.11$, lower $95 \% \mathrm{CI}=2.08$, upper $95 \% \mathrm{CI}=8.11, P<0.001$; Fig. $4 \mathrm{c}$ ) in trials with $O$. niloticus as the stimulus. The mean body size of $O$. amphimelas pairs had no significant effect on the likelihood of leaving shelter (coef $=0.03$, $\exp (-$ coef) $=1.03$, lower $95 \% \mathrm{CI}=1$, upper $95 \% \mathrm{CI}=$ $1.07, P=0.064)$, entering the stimulus zone $($ coef $=$ $0.02, \exp ($ coef $)=1.02$, lower $95 \% \mathrm{CI}=0.98$, upper 

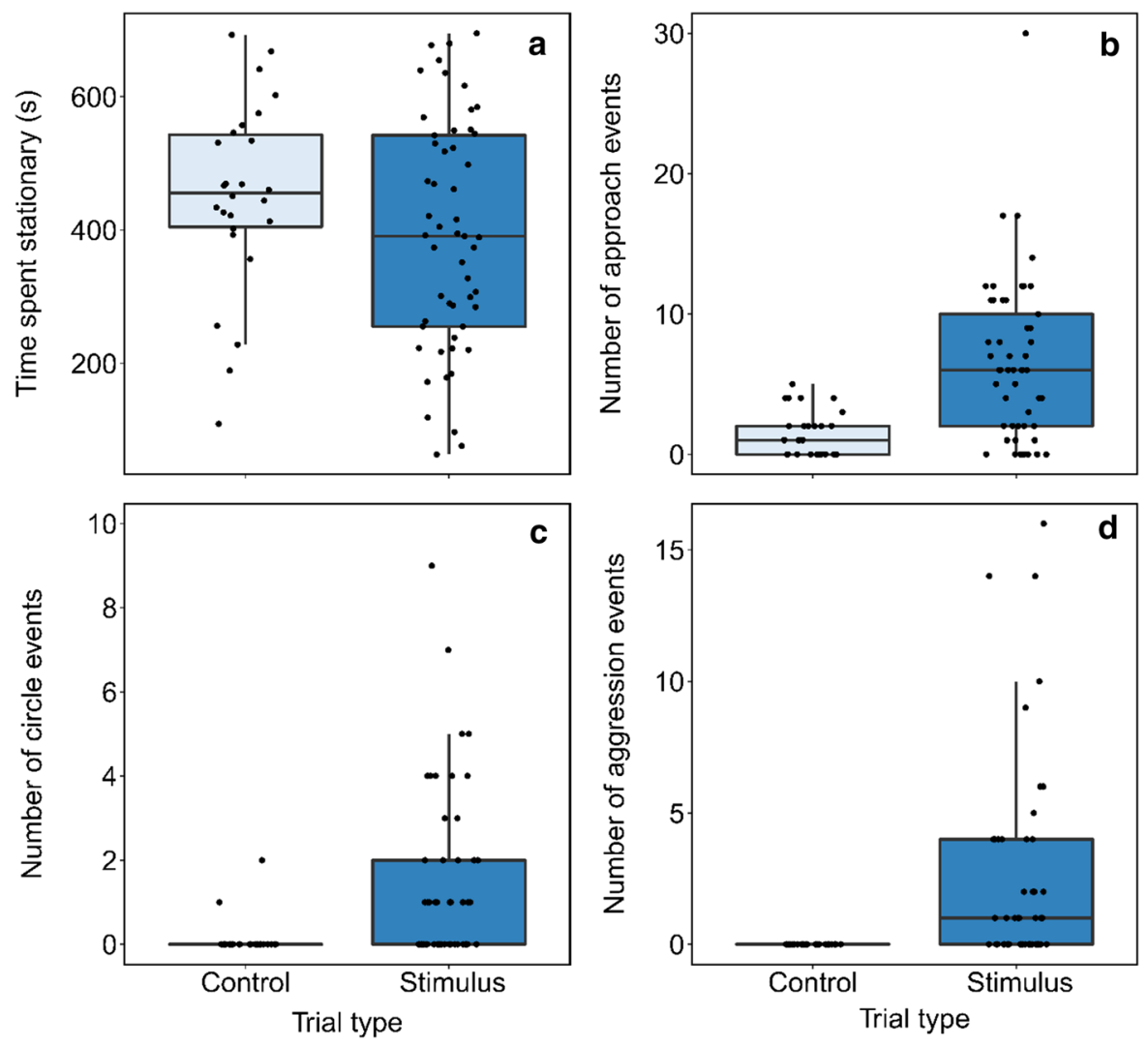

Fig. 3 Box plots showing a time spent stationary, b number of approach events, $\mathbf{c}$ number of circle events, and d) number of aggression events by the focal $O$. niloticus subject in experiment one. The distance between the top and bottom of each box represents interquartile range, whiskers extend to data points

95\% CI $=1.05, P=0.33$ ), or approaching the stimulus $($ coef $=0.02, \exp ($ coef $)=1.02$, lower $95 \% \mathrm{CI}=$ 0.99 , upper $95 \% \mathrm{CI}=1.06, P=0.21)$. In the stimulus trials only, the body size of stimulus $O$. niloticus did not affect the likelihood of leaving shelter (coef = 0.0007 , $\exp ($ coef $)=0.99$, lower $95 \% \quad \mathrm{CI}=0.97$, upper $95 \% \mathrm{CI}=1.03, P=0.96)$, entering the stimulus zone $($ coef $=-0.0008, \exp ($ coef $)=0.99$, lower $95 \%$ $\mathrm{CI}=0.96$, upper $95 \% \mathrm{CI}=1.04, \quad P=0.97)$, or approaching the stimulus (coef $=-0.006$, $\exp (-$ coef) $=0.99$, lower $95 \% \mathrm{CI}=0.96$, upper $95 \% \mathrm{CI}=$ 1.03, $P=0.77)$.

Sociability

AICc values and Akaike weights indicated strong support for the null model (Table 4), suggesting no effect of treatment or focal body size on the time spent

within 1.5 times the interquartile range, and the line through the centre of each box represents the median. Individual data points are scattered over their corresponding treatment with added jitter for clarity and those above or below the whiskers represent outliers

in the same zone by $O$. amphimelas subjects (Fig. 5a). In the stimulus trials only, AICc values and Akaike weights also indicated strong support for the null model, suggesting no effect of stimulus body size on the sociability of $O$. amphimelas pairs (Table 5).

\section{Activity}

For the time spent stationary, AICc values and Akaike weights indicated strongest support for the model containing only treatment as a fixed effect (Table 4), however, the AICc of the null model was within 1.2 units suggesting only weak evidence for the main effect of treatment (Fig. 5b). In the stimulus trials only, AICc values and Akaike weights indicated strongest support for the null model, suggesting no effect of stimulus body size on the time spent stationary by focal $O$. amphimelas pairs (Table 5). 
Table 3 Model comparisons for GLMs used in experiment one to analyse how the dependent variables of $O$. niloticus activity, approach, circle, and aggression events were affected by five different combinations of the covariates stimulus body size and focal body size in the stimulus trials only

\begin{tabular}{|c|c|c|c|c|c|c|}
\hline Dependent variable & Model & Explanatory variables & $\mathrm{AICc}$ & $\Delta \mathrm{AICc}$ & df & Akaike weight \\
\hline \multirow[t]{5}{*}{ Activity (Negative binomial) } & $\mathrm{m} 4$ & Focal body size & 701.2 & 0 & 3 & 0.5 \\
\hline & $\mathrm{m} 2$ & Stimulus body size + Focal body size & 703.2 & 2 & 4 & 0.18 \\
\hline & $\mathrm{m} 5$ & Null & 703.3 & 2.1 & 2 & 0.17 \\
\hline & $\mathrm{m} 3$ & Stimulus body size & 704.7 & 3.6 & 3 & 0.08 \\
\hline & $\mathrm{m} 1$ & Stimulus body size $*$ Focal body size & 705.3 & 4.1 & 5 & 0.06 \\
\hline \multirow[t]{5}{*}{ Approach events (Negative binomial) } & $\mathrm{m} 1$ & Stimulus body size $*$ Focal body size & 311.5 & 0 & 5 & 0.37 \\
\hline & $\mathrm{m} 3$ & Stimulus body size & 312.9 & 1.4 & 3 & 0.19 \\
\hline & $\mathrm{m} 2$ & Stimulus body size + Focal body size & 312.9 & 1.4 & 4 & 0.19 \\
\hline & $\mathrm{m} 5$ & Null & 313.6 & 2 & 2 & 0.13 \\
\hline & $\mathrm{m} 4$ & Focal body size & 313.7 & 2.2 & 3 & 0.12 \\
\hline \multirow[t]{5}{*}{ Circle events (Negative binomial) } & $\mathrm{m} 5$ & Null & 172.2 & 0 & 2 & 0.39 \\
\hline & $\mathrm{m} 4$ & Focal body size & 172.7 & 0.5 & 3 & 0.31 \\
\hline & $\mathrm{m} 3$ & Stimulus body size & 174.3 & 2.1 & 3 & 0.14 \\
\hline & $\mathrm{m} 2$ & Stimulus body size + Focal body size & 174.6 & 2.4 & 4 & 0.11 \\
\hline & $\mathrm{m} 1$ & Stimulus body size $*$ Focal body size & 176.6 & 4.4 & 5 & 0.04 \\
\hline \multirow[t]{5}{*}{ Aggression events (Negative binomial) } & $\mathrm{m} 4$ & Focal body size & 203.8 & 0 & 3 & 0.36 \\
\hline & $\mathrm{m} 5$ & Null & 204.7 & 0.9 & 2 & 0.23 \\
\hline & $\mathrm{m} 2$ & Stimulus body size + Focal body size & 205.1 & 1.3 & 4 & 0.18 \\
\hline & $\mathrm{m} 3$ & Stimulus body size & 206 & 2.2 & 3 & 0.12 \\
\hline & $\mathrm{m} 1$ & Stimulus body size $*$ Focal body size & 206.2 & 2.3 & 5 & 0.11 \\
\hline
\end{tabular}

Trial type: : Control - Stimulus
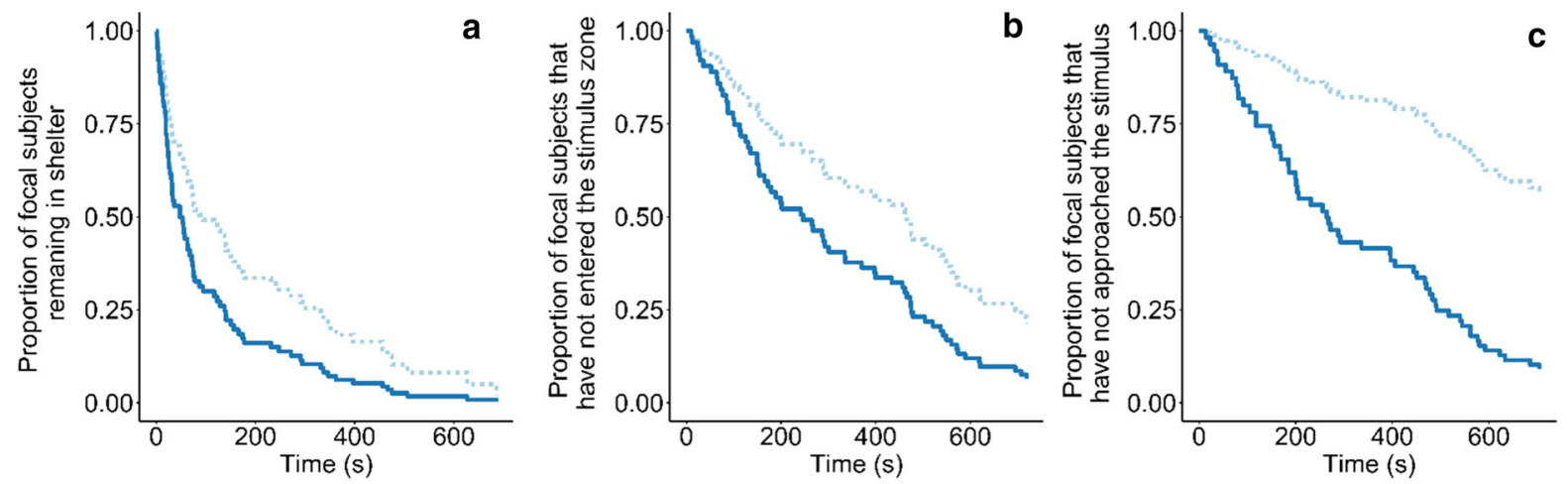

Fig. 4 The likelihood of $O$. amphimelas $\mathbf{a}$ leaving the shelter, $\mathbf{b}$ entering the stimulus zone, and $\mathbf{c}$ approaching the stimulus in control and stimulus trials in experiment two

Approach events

The model with treatment and focal body size as fixed effects had the strongest support according to the AICc
(Table 4), where approach events were significantly more likely in stimulus trials (Fig. 5c), and the size of focal $O$. amphimelas significantly affected the number of approaches, with larger $O$. amphimelas making 
Table 4 Model comparisons for GLMs used to analyse how the dependent variables of $O$. amphimelas sociability, activity, dart events and approach events were affected by five different combinations of the fixed effects treatment and focal body size

\begin{tabular}{|c|c|c|c|c|c|c|}
\hline Dependent variable & Model & Explanatory variables & $\mathrm{AICc}$ & $\triangle \mathrm{AICc}$ & df & Akaike weight \\
\hline \multirow[t]{5}{*}{ Sociability (Gaussian) } & $\mathrm{m} 5$ & Null & 965.1 & 0 & 2 & 0.52 \\
\hline & $\mathrm{m} 4$ & Focal body size & 967 & 1.9 & 3 & 0.2 \\
\hline & $\mathrm{m} 3$ & Treatment & 967.1 & 2 & 3 & 0.19 \\
\hline & $\mathrm{m} 2$ & Treatment + Focal body size & 669.1 & 4 & 4 & 0.07 \\
\hline & $\mathrm{m} 1$ & Treatment $*$ Focal body size & 671.4 & 6.3 & 5 & 0.02 \\
\hline \multirow[t]{5}{*}{ Activity (Negative binomial) } & $\mathrm{m} 3$ & Treatment & 878.2 & 0 & 3 & 0.44 \\
\hline & $\mathrm{m} 5$ & Null & 879.3 & 1.2 & 2 & 0.24 \\
\hline & $\mathrm{m} 2$ & Treatment + Focal body size & 880.3 & 2.1 & 4 & 0.15 \\
\hline & $\mathrm{m} 4$ & Focal body size & 880.9 & 2.8 & 3 & 0.11 \\
\hline & $\mathrm{m} 1$ & Treatment $*$ Focal body size & 882.1 & 3.9 & 5 & 0.06 \\
\hline \multirow[t]{5}{*}{ Number of approaches (Negative binomial) } & $\mathrm{m} 2$ & Treatment + Focal body size & 352.4 & 0 & 4 & 0.61 \\
\hline & $\mathrm{m} 1$ & Treatment $*$ Focal body size & 353.3 & 0.9 & 5 & 0.39 \\
\hline & $\mathrm{m} 3$ & Treatment & 363.8 & 11.4 & 3 & 0.002 \\
\hline & $\mathrm{m} 4$ & Focal body size & 396.9 & 44.5 & 3 & $<0.001$ \\
\hline & $\mathrm{m} 5$ & Null & 405 & 52.6 & 2 & $<0.001$ \\
\hline \multirow[t]{5}{*}{ Dart events (Binomial) } & $\mathrm{m} 3$ & Treatment & 68.6 & 0 & 2 & 0.54 \\
\hline & $\mathrm{m} 2$ & Treatment + Focal body size & 69.5 & 0.9 & 3 & 0.35 \\
\hline & $\mathrm{m} 1$ & Treatment $*$ Focal body size & 71.7 & 3.1 & 4 & 0.11 \\
\hline & $\mathrm{m} 4$ & Focal body size & 102.2 & 33.6 & 2 & $<0.001$ \\
\hline & $\mathrm{m} 5$ & Null & 102.7 & 34.1 & 1 & $<0.001$ \\
\hline
\end{tabular}

more approaches. In the stimulus trials only, AICc values and Akaike weights indicated strong support for the model containing only focal body size as a covariate. This further highlights the significant effect of focal subject body size on the number of approach events, while suggesting no effect of stimulus body size (Table 5).

\section{Dart events}

In the models for the likelihood of a dart event occurring during a trial, AICc values indicated strong support for the model containing only treatment as a fixed-effect (Table 4), where dart events were more likely to occur in stimulus trials than control trials (Fig. 5d). In stimulus trials, AICc values and Akaike weights indicated strongest support for the null model, suggesting no effect of stimulus body size on the likelihood of dart events occurring (Table 5).

\section{Discussion}

In experiment one, $O$. niloticus were more likely to approach and circle the stimulus when the stimulus chamber contained the $O$. amphimelas pair rather than when it was empty. A larger number of approach, circle and aggression events also occurred in these stimulus trials. Thus, despite limited experience interacting with $O$. amphimelas, $O$. niloticus were readily antagonistic towards them, suggesting that aggression towards juvenile $O$. amphimelas by adult $O$. niloticus is likely during novel encounters. In experiment two, the sociability of the $O$. amphimelas pair was unaffected by the presence of $O$. niloticus, and there was little evidence for a difference in activity between stimulus and control trials. Under the risk of potential predation, reduced activity (Sanches et al. 2015; Miyai et al. 2016; Ioannou et al. 2017) and increased sociability (Ioannou 2020; Romenskyy et al. 2020) are known behavioural responses, however neither were observed in this experiment when the stimulus chamber contained the $O$. niloticus. This 

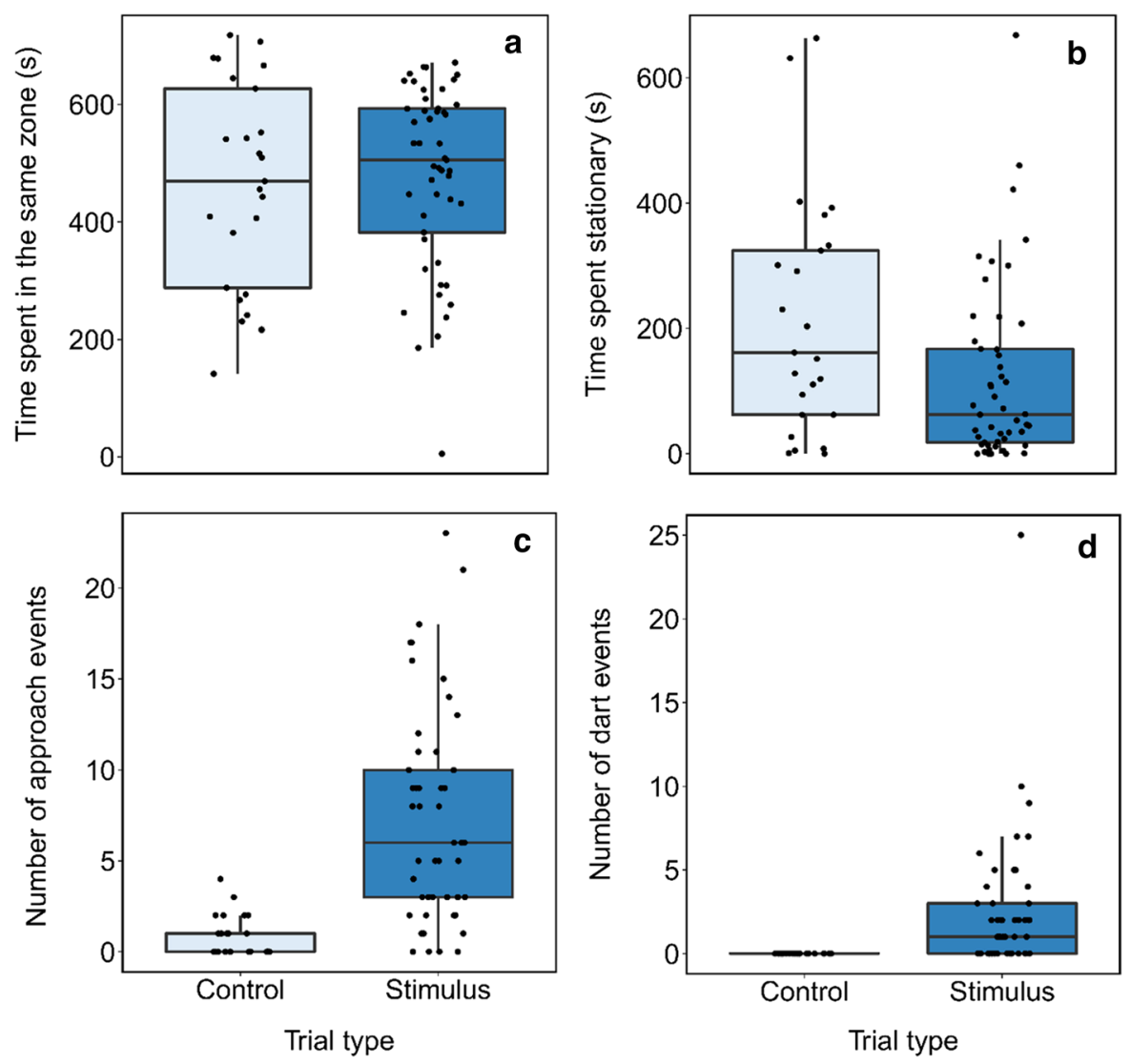

Fig. 5 Box plots showing a time spent by $O$. amphimelas in the same zone with the conspecific, b time $O$. amphimelas spent stationary, c number of approach events by $O$. amphimelas, and d number of dart events by the focal $O$. amphimelas in experiment two. The distance between the top and bottom of each box represents interquartile range, whiskers extend to data

apparent lack of a response to the potential threat from $O$. niloticus is further highlighted by the fact that $O$. amphimelas entered the stimulus zone and approached the stimulus more readily when it contained an $O$. niloticus, suggesting that naïve individuals of native species may readily approach $O$. niloticus, a behavioural response which would increase the frequency of interactions. O. amphimelas also showed more frequent darting during stimulus trials but these were never observed in control trials. Darting is a rapid locomotory response which often occurs when fish are startled by a threat (McCormick et al. 2019). Thus, while $O$. amphimelas showed a lack of fear in approaching the stimulus chamber when it contained an $O$. niloticus, this often resulted in an energetically costly dart response.

points within 1.5 times the interquartile range, and the line through the centre of each box represents the median. Individual data points are scattered over their corresponding treatment with added jitter for clarity and those above or below the whiskers represent outliers

The response of $O$. amphimelas in this experiment demonstrates how naïveté to a novel competitor may result in maladaptive behavioural responses by nonnative species. The aggression shown by $O$. niloticus in experiment one is in accordance with previous research demonstrating the tendency of $O$. niloticus to be aggressive to other species (Martin et al. 2010; Sanches et al. 2012), including O. amphimelas (Champneys et al. 2020). Such studies have demonstrated how interactions between $O$. niloticus and native species may lead to harmful outcomes including competition-induced restricted access to resources, increased predation, and parasite transfer (Jiménez-García et al. 2001; Martin et al. 2010). These are a consequence of direct antagonistic interactions, thus native species may reduce the impact of $O$. 
Table 5 Model comparisons for GLMs used to analyse how the dependent variables of $O$. amphimelas sociability, activity, dart events and approach events were affected by five different combinations of the covariates stimulus body size and focal body size in the stimulus trials only

\begin{tabular}{|c|c|c|c|c|c|c|}
\hline Dependent variable & Model & Explanatory variables & $\mathrm{AICc}$ & $\Delta \mathrm{AICc}$ & df & Akaike weight \\
\hline \multirow[t]{5}{*}{ Sociability (Negative binomial) } & $\mathrm{m} 5$ & Null & 667 & 0 & 2 & 0.54 \\
\hline & $\mathrm{m} 3$ & Stimulus body size & 669.1 & 2.1 & 3 & 0.19 \\
\hline & $\mathrm{m} 4$ & Focal body size & 669.1 & 2.2 & 3 & 0.19 \\
\hline & $\mathrm{m} 2$ & Stimulus body size + Focal body size & 671.3 & 4.3 & 4 & 0.06 \\
\hline & $\mathrm{m} 1$ & Stimulus body size $*$ Focal body size & 673.7 & 6.8 & 5 & 0.02 \\
\hline \multirow[t]{5}{*}{ Activity (Negative binomial) } & $\mathrm{m} 5$ & Null & 559.1 & 0 & 2 & 0.5 \\
\hline & $\mathrm{m} 3$ & Stimulus body size & 560.5 & 1.4 & 3 & 0.24 \\
\hline & $\mathrm{m} 4$ & Focal body size & 561.3 & 2.3 & 3 & 0.16 \\
\hline & $\mathrm{m} 2$ & Stimulus body size + Focal body size & 562.8 & 3.8 & 4 & 0.08 \\
\hline & $\mathrm{m} 1$ & Stimulus body size $*$ Focal body size & 564.8 & 5.8 & 5 & 0.03 \\
\hline \multirow[t]{5}{*}{ Number of approaches (Negative binomial) } & $\mathrm{m} 4$ & Focal body size & 291.4 & 0 & 3 & 0.7 \\
\hline & $\mathrm{m} 2$ & Stimulus body size + Focal body size & 293.8 & 2.3 & 4 & 0.22 \\
\hline & $\mathrm{m} 1$ & Stimulus body size $*$ Focal body size & 296.1 & 4.7 & 5 & 0.07 \\
\hline & $\mathrm{m} 5$ & Null & 299.9 & 8.4 & 2 & 0.01 \\
\hline & $\mathrm{m} 3$ & Stimulus body size & 302.1 & 10.7 & 3 & 0.003 \\
\hline \multirow[t]{5}{*}{ Dart events (Binomial) } & m5 & Null & 66.5 & 0 & 1 & 0.42 \\
\hline & $\mathrm{m} 4$ & Focal body size & 67.4 & 0.9 & 2 & 0.27 \\
\hline & $\mathrm{m} 3$ & Stimulus body size & 68.3 & 1.8 & 2 & 0.18 \\
\hline & $\mathrm{m} 2$ & Stimulus body size + Focal body size & 69.4 & 2.8 & 3 & 0.1 \\
\hline & $\mathrm{m} 1$ & Stimulus body size $*$ Focal body size & 71.7 & 5.2 & 4 & 0.03 \\
\hline
\end{tabular}

niloticus through avoidance behaviours. Oreochromis amphimelas showed a lack of threat perception in the presence of $O$. niloticus until they reached very close proximity with the stimulus chamber where they often showed darting responses (Kimbell and Morrell 2015). The stimulus chamber prevented physical aggression between the two species; however under natural conditions, such approaches would likely result in direct agonistic interactions, which could lead to injury or unnecessary energy expenditure from flight responses such as darting. Thus, the failure to detect the potential threat of $O$. niloticus, until within very close proximity, may drive harmful impacts for naïve native species.

In experiment one, larger $O$. niloticus were more active and were less aggressive towards the $O$. amphimelas pair. Oreochromis niloticus also approached more frequently when the $O$. amphimelas were larger. Similarly, in experiment two, larger $O$. amphimelas made more approaches in stimulus trials. Previous research has shown that $O$. niloticus are highly aggressive towards $O$. amphimelas when they are similar sizes (Champneys et al. 2020). Given that the $O$. niloticus were considerably larger than the $O$. amphimelas in this experiment, increased aggression and approaches when the two species were more similarly sized (smaller $O$. niloticus and larger $O$. amphimelas) is in accordance with prior research. $O$. niloticus are much larger than the majority of native tilapia species in Tanzania (Shechonge et al. 2019), and the results of this experiment suggest that aggression may be reduced as body size differences increase. Conservation measures may therefore be targeted towards limiting the impact of $O$. niloticus on the largest-bodied native species.

Research suggests that naïveté is thought to be lower in response to congeneric or functionally similar species (Anton et al. 2020) because native species may recognise traits which are similar to those of species to which they have had eco-evolutionary exposure (Cox and Lima 2006). The experimental subjects used in this study are congeneric tilapia species and are both 
maternal mouthbrooders and microphagous, suggesting functional similarity (Trewavas and Fryer 1965). This similarity may reduce naïveté and prevent maladaptive responses to invasive species. However, ecological similarity may also benefit the invasive species, by causing it to be well adapted to the novel ecosystem enabling it to exploit available resources and thrive as a result. The majority of research on this topic has focused on predator-prey naivete, and future work could benefit understanding of how these principles may apply to naivete of a native species towards a non-native competitor. Research has shown that $O$. niloticus can be conditioned to show an antipredatory response to a novel predator stimulus under experimental conditions (Mesquita and Young 2007), suggesting that species within this genus may learn to recognise threats following sufficient exposure. Thus, studies assessing the cognitive abilities of native tilapia species would benefit our understanding of the impact of naivete during invasions, given that rapid behavioural adaptation to novel enemies could greatly limit their negative impacts.

The results of this study highlight how naivete during interactions with $O$. niloticus could drive harmful impacts for $O$. amphimelas, and other native fish species. Currently, very little is known about the timing or impacts of this specific invasion in situ, and this is the case for many O.niloticus invasions across its non-native range. Given that declines of native species following the introduction of $O$. niloticus have been reported in several areas including Tanzania (Canonico et al. 2005), future research focusing on how naivete may impact early interactions with $O$. niloticus could help target conservation efforts towards vulnerable populations and aid policy decisions which may limit the further spread of this species.

Author contributions CCI, TC, KF, and ST conceived and designed the experiments. $\mathrm{KF}$ and $\mathrm{ST}$ performed the experiments. KF and ST reviewed video footage and recorded the behaviours. TC and CCI analysed the data. TC wrote the manuscript, with editorial advice from CCI and MG.

Funding This project was funded by a NERC GW4 FRESH CDT PhD studentship awarded to TC (NE/R011524/1) and we are thankful to the GW4 FRESH Centre for Doctoral Training in Freshwater Biosciences and Sustainability for their support of this project. This research was also funded by a Natural
Environment Research Council grant (NE/P012639/1) awarded to CCI.

Data availability The datasets generated during and/or analysed during the current study are available in the supplementary material, video files and code are available upon from the corresponding author on reasonable request.

\section{Declarations}

Conflict of interest The authors have no financial or proprietary interests in any material discussed in this article nor any other conflicts of interest to declare.

Ethical approval The experimental procedures and housing conditions used in this study were in accordance with the ethical standards of the University of Bristol and ethical approval was granted by the University's Animal Welfare and Ethical Review Body (UIN number: UB 18 067). All authors have given their permission for the submission of this manuscript.

Open Access This article is licensed under a Creative Commons Attribution 4.0 International License, which permits use, sharing, adaptation, distribution and reproduction in any medium or format, as long as you give appropriate credit to the original author(s) and the source, provide a link to the Creative Commons licence, and indicate if changes were made. The images or other third party material in this article are included in the article's Creative Commons licence, unless indicated otherwise in a credit line to the material. If material is not included in the article's Creative Commons licence and your intended use is not permitted by statutory regulation or exceeds the permitted use, you will need to obtain permission directly from the copyright holder. To view a copy of this licence, visit http://creativecommons.org/licenses/by/4.0/.

\section{References}

Anton A, Geraldi NR, Lovelock CE et al (2019) Global ecological impacts of marine exotic species. Nat Ecol Evol 3:787-800. https://doi.org/10.1038/s41559-019-0851-0

Anton A, Geraldi NR, Ricciardi A, Dick JTA (2020) Global determinants of prey naiveté to exotic predators. Proc R Soc B Biol Sci 287:20192978. https://doi.org/10.1098/ rspb.2019.2978

Bevan PA, Gosetto I, Jenkins ER et al (2018) Regulation between personality traits: individual social tendencies modulate whether boldness and leadership are correlated. Proc R Soc B Biol Sci 285:20180829. https://doi.org/10. 1098/rspb.2018.0829

Bleeker W, Schmitz U, Ristow M (2007) Interspecific hybridisation between alien and native plant species in Germany and its consequences for native biodiversity. Biol Conserv 137:248-253. https://doi.org/10.1016/j.biocon.2007.02. 004

Bolker B, R Core Team (2017) bbmle: tools for general maximum likelihood estimation 
Burnham KP, Anderson DR (2004) Multimodel inference: understanding AIC and BIC in model selection. Sociol Methods Res 33:261-304. https://doi.org/10.1177/ 0049124104268644

Canonico GC, Arthington A, Mccrary JK, Thieme ML (2005) The effects of introduced tilapias on native biodiversity. Aquat Conserv Mar Freshw Ecosyst 15:463-483. https:// doi.org/10.1002/aqc.699

Carthey AJR, Banks PB (2014) Naïveté in novel ecological interactions: lessons from theory and experimental evidence. Biol Rev 89:932-949. https://doi.org/10.1111/brv. 12087

Carthey AJR, Blumstein DT (2018) Predicting predator recognition in a changing world. Trends Ecol Evol 33:106-115. https://doi.org/10.1016/j.tree.2017.10.009

Chalkowski K, Lepczyk CA, Zohdy S (2018) Parasite ecology of invasive species: conceptual framework and new hypotheses. Trends Parasitol 34:655-663. https://doi.org/ 10.1016/j.pt.2018.05.008

Champneys T, Castaldo G, Consuegra S, Garcia De Leaniz C (2018) Density-dependent changes in neophobia and stress-coping styles in the world's oldest farmed fish. R Soc Open Sci 5:181473. https://doi.org/10.1098/rsos.181473

Champneys T, Genner MG, Ioannou CC (2020) Invasive Nile tilapia dominates a threatened indigenous tilapia in competition over shelter. Hydrobiologia 8:1-16. https://doi. org/10.1007/s10750-020-04341-8

Chapple DG, Simmonds SM, Wong BBM (2012) Can behavioral and personality traits influence the success of unintentional species introductions? Trends Ecol Evol 27:57-64. https://doi.org/10.1016/j.tree.2011.09.010

Clavero M, García-Berthou E (2005) Invasive species are a leading cause of animal extinctions. Trends Ecol Evol 20:110. https://doi.org/10.1016/j.tree.2005.01.003

Cox JG, Lima SL (2006) Naiveté and an aquatic-terrestrial dichotomy in the effects of introduced predators. Trends Ecol Evol 21:674-680. https://doi.org/10.1016/j.tree.2006. 07.011

de Oliveira Mesquita F, Young RJ (2007) The behavioural responses of Nile tilapia (Oreochromis niloticus) to antipredator training. Appl Anim Behav Sci 106:144-154. https://doi.org/10.1016/j.applanim.2006.06.013

Favero Neto J, Giaquinto PC (2020) Environmental enrichment techniques and tryptophan supplementation used to improve the quality of life and animal welfare of Nile tilapia. Aquac Reports 17:100354. https://doi.org/10.1016/ j.aqrep.2020.100354

Friard O, Gamba M (2016) BORIS: a free, versatile open-source event-logging software for video/audio coding and live observations. Methods Ecol Evol 7:1325-1330. https://doi. org/10.1111/2041-210X.12584

Frommen JG, Hiermes M, Bakker TCM (2009) Disentangling the effects of group size and density on shoaling decisions of three-spined sticklebacks (Gasterosteus aculeatus). Behav Ecol Sociobiol 63:1141-1148. https://doi.org/10. 1007/s00265-009-0767-9

Harrington LA, Harrington AL, Yamaguchi N et al (2009) The impact of native competitors on an alien invasive: Temporal niche shifts to avoid interspecific aggression? Ecology 90:1207-1216. https://doi.org/10.1890/08-0302.1
Heavener SJ, Carthey AJR, Banks PB (2014) Competitive naïveté between a highly successful invader and a functionally similar native species. Oecologia 175:73-84. https://doi. org/10.1007/s00442-013-2874-6

Ioannou CC (2020) Grouping and Predation. Encycl Evol Psychol Sci. https://doi.org/10.1007/978-3-319-16999-6

Ioannou CC, Ramnarine IW, Torney CJ (2017) High-predation habitats affect the social dynamics of collective exploration in a shoaling fish. Sci Adv. https://doi.org/10.1126/sciadv. 1602682

Jiménez-García MI, Vidal-Martínez VM, López-Jiménez S (2001) Monogeneans in introduced and native cichlids in México: Evidence for transfer. J Parasitol 87:907-909. https://doi.org/10.1645/0022-3395(2001)087[0907: MIIANC]2.0.CO;2

Kassambara A, Kosinski M, Biecek P (2019) survminer: drawing survival curves using "ggplot2"

Kimbell HS, Morrell LJ (2015) Turbidity influences individual and group level responses to predation in guppies, Poecilia reticulata. Anim Behav 103:179-185. https://doi.org/10. 1016/j.anbehav.2015.02.027

Kolar CS, Lodge DM (2001) Progress in invasion biology: predicting invaders. Trends Ecol Evol 16:199-204. https:// doi.org/10.1016/S0169-5347(01)02101-2

Kulhanek SA, Ricciardi A, Leung B (2011) Is invasion history a useful tool for predicting the impacts of the world's worst aquatic invasive species? Ecol Appl 21:189-202. https:// doi.org/10.1890/09-1452.1

Letnic M, Webb JK, Shine R (2008) Invasive cane toads (Bufo marinus) cause mass mortality of freshwater crocodiles (Crocodylus johnstoni) in tropical Australia. Biol Conserv 141:1773-1782. https://doi.org/10.1016/j.biocon.2008.04. 031

Llewelyn JS, Phillips BL, Shine R (2009) Sublethal costs associated with the consumption of toxic prey by snakes. Austral Ecol 34:179-184. https://doi.org/10.1111/j.14429993.2008.01919.x

Martin CW, Valentine MM, Valentine JF (2010) Competitive interactions between invasive nile tilapia and native fish: The potential for altered trophic exchange and modification of food webs. PLoS ONE 5:57-59. https://doi.org/10.1371/ journal.pone.0014395

McCormick MI, Fakan EP, Nedelec SL, Allan BJM (2019) Effects of boat noise on fish fast-start escape response depend on engine type. Sci Rep 9:1-10. https://doi.org/10. 1038/s41598-019-43099-5

Miyai CA, Sanches FHC, Pinho-Neto CF, Barreto RE (2016) Effects of predator odour on antipredator responses of Nile tilapia. Physiol Behav 165:22-27. https://doi.org/10.1016/ j.physbeh.2016.06.033

Papacostas KJ, Freestone AL (2019) Multi-trophic native and non-native prey naiveté shape marine invasion success. PLoS ONE 14:1-14. https://doi.org/10.1371/journal.pone. 0221969

Parker IM, Lonsdale WM, Goodell K et al (1999) Impact: toward a framework for understanding the ecological effects of invaders. Biol Invasions 1:3-19

Phillips BL, Shine R (2004) Adapting to an invasive species: toxic cane toads induce morphological change in Australian snakes. Proc Natl Acad Sci U S A 
101:17150-17155. https://doi.org/10.1073/pnas. 0406440101

R Core Team (2020) R: A language and environment for statistical computing

Richardson DM, Pyšek P, Rejmánek M et al (2000) Naturalization and invasion of alien plants: concepts and definitions. Divers Distrib 6:93-107. https://doi.org/10.1046/j. 1472-4642.2000.00083.x

Robbins TR, Freidenfelds NA, Langkilde T (2013) Native predator eats invasive toxic prey: evidence for increased incidence of consumption rather than aversion-learning. Biol Invasions 15:407-415. https://doi.org/10.1007/ s10530-012-0295-9

Romenskyy M, Herbert-Read JE, Ioannou CC et al (2020) Quantifying the structure and dynamics of fish shoals under predation threat in three dimensions. Behav Ecol 31:311-321. https://doi.org/10.1093/beheco/arz197

Ros AFH, Becker K, Oliveira RF (2006) Aggressive behaviour and energy metabolism in a cichlid fish, Oreochromis mossambicus. Physiol Behav 89:164-170. https://doi.org/ 10.1016/j.physbeh.2006.05.043

Roshani D, Ghaderi E (2016) Comparing smoothing techniques for fitting the nonlinear effect of covariate in cox models. Acta Inform Medica 24:38-41. https://doi.org/10.5455/ aim.2016.24.38-41

Rowles AD, O'Dowd DJ (2007) Interference competition by Argentine ants displaces native ants: Implications for biotic resistance to invasion. Biol Invasions 9:73-85. https://doi. org/10.1007/s10530-006-9009-5

Salo P, Korpimäki E, Banks PB et al (2007) Alien predators are more dangerous than native predators to prey populations. Proc R Soc B Biol Sci 274:1237-1243. https://doi.org/10. 1098/rspb.2006.0444

Sanches FHC, Miyai CA, CostaTâ TM et al (2012) Aggressiveness overcomes body-size effects in fights staged between invasive and native fish species with overlapping niches. PLoS ONE 7:e29746. https://doi.org/10.1371/ journal.pone.0029746

Sanches FHC, Miyai CA, Pinho-Neto CF, Barreto RE (2015) Stress responses to chemical alarm cues in Nile tilapia.
Physiol Behav 149:8-13. https://doi.org/10.1016/j. physbeh.2015.05.010

Sax DF, Gaines SD (2008) Species invasions and extinction: the future of native biodiversity on islands. Proc Natl Acad Sci 105:11490-11497. https://doi.org/10.17226/12501

Schlaepfer MA, Sax DF, Olden JD (2011) The potential conservation value of non-native species. Conserv Biol 25:428-437. https://doi.org/10.1111/j.1523-1739.2010. 01646.x

Schlaepfer MA, Sherman PW, Blossey B, Runge MC (2005) Introduced species as evolutionary traps. Ecol Lett 8:241-246. https://doi.org/10.1111/j.1461-0248.2005. 00730.x

Shechonge A, Ngatunga BP, Bradbeer SJ et al (2019) Widespread colonisation of Tanzanian catchments by introduced Oreochromis tilapia fishes: the legacy from decades of deliberate introduction. Hydrobiologia 832:235-253. https://doi.org/10.1007/s10750-018-3597-9

Szopa-Comley AW, Donald WG, Ioannou CC (2020) Predator personality and prey detection: inter-individual variation in responses to cryptic and conspicuous prey. Behav Ecol Sociobiol. https://doi.org/10.1007/s00265-020-02854-9

Therneau TM (2020) A package for survival analysis in $\mathrm{R}$

Trewavas E, Fryer G (1965) Species of Tilapia (Pisces, Cichlidae) in Lake Kitangiri, Tanzania, East Africa. Proc Zool Soc London 147:108-118

Venables B, Ripley B (2002) Modern applied statistics with S, 4th edn. Springer, New York

Wagenmakers EJ, Farrell S (2004) AIC model selection using Akaike weights. Psychon Bull Rev 11:192-196. https://doi. org/10.3758/BF03206482

Wing JDB, Champneys TS, Ioannou CC (2020) The impact of turbidity on foraging and risk taking in the invasive Nile tilapia (Oreochromis niloticus) and a threatened native cichlid (Oreochromis amphimelas). bioRxiv https://doi. org/10.1101/2020.07.23.217513

Publisher's Note Springer Nature remains neutral with regard to jurisdictional claims in published maps and institutional affiliations. 